\title{
Envelhecimento acelerado de sementes de alface produzidas no manejo orgânico em cultivo protegido e a céu aberto
}

Antônio Amorim Brandão

Higino Marcos Lopes²

\section{Resumo}

As sementes de alface podem ser produzidas em condições naturais a pleno sol ou em casas de vegetação, onde o ambiente de cultivo pode interferir no vigor das sementes. Neste contexto, o envelhecimento acelerado com solução salina de $\mathrm{NaCl}$ (EASS) tem-se mostrado eficiente para determinação da qualidade das sementes. Desta forma, objetivou-se avaliar a influência do ambiente de cultivo e de cultivares no vigor das sementes de alface produzidas no manejo orgânico e em dois municípios do estado do Rio de Janeiro. Utilizou-se de delineamento inteiramente casualizado, em esquema fatorial $(2 \times 7)$, com 4 repetições, sendo dois ambientes (cultivo protegido e céu aberto) e sete cultivares de alface. 0 experimento foi conduzido em Seropédica e Avelar (RJ) e avaliados separadamente. As sementes foram submetidas ao teste de envelhecimento acelerado com solução saturada de $\mathrm{NaCl}$. As sementes foram mantidas em câmara úmida com solução salina por $72 \mathrm{~h}$ a $41^{\circ} \mathrm{C}$. Após o período de envelhecimento, as sementes foram colocadas para germinar. Determinou-se a umidade das sementes antes e após o envelhecimento. Houve diferenças entre o grau de umidade das sementes pré-EASS no município de Seropédica e pós-EASS em Avelar. Pelo teste de EASS, conclui-se que a segunda contagem do teste de germinação possibilitou separar melhor os lotes de sementes de alface. A produção em cultivo protegido proporcionou sementes de maior vigor, tanto em Seropédica, quanto em Avelar. Entretanto, as cultivares Grand Rapids e Maravilha Quatro Estações produziram sementes de alto vigor em ambos ambientes de cultivo.

Palavras-chave: Vigor. Hortaliças. Lactuca sativa L.

\section{Introdução}

A alface é uma das mais importantes espécies olerícolas produzidas, tanto em volume de produção quanto em renda financeira, estando entre as cinco primeiras nesses quesitos (ASSOCIAÇÃO BRASILEIRA DE COMÉRCIO DE SEMENTES E MUDAS - ABCSEM, 2014). Essa importância reflete diretamente na demanda por sementes. No ano de 2012, a alface ocupou a quinta posição em volume de sementes comercializadas no Brasil (ABCSEM, 2014), sendo a folhosa mais cultivada em sistema convencional e orgânico.

1 Universidade Federal Rural do Rio de Janeiro, pós-graduação em Fitotecnia, doutorando, toniagrick@hotmail.com. BR 465, Km 07, Seropédica, RJ, CEP 23851-970.

2 Universidade Federal Rural do Rio de Janeiro, Instituto de Agronomia; Departamento de Fitotecnia, professor titular. higinomlopes@gmail.com. 
Ao passo que aumenta a consciência do mercado consumidor com relação à segurança alimentar, em especial os produtos hortícolas com resíduos de agrotóxicos, cresce a demanda por orgânicos. Porém, atualmente o mercado de sementes orgânicas é incipiente e não atende à crescente demanda, ficando o agricultor obrigado a utilizar sementes convencionais em seus cultivos (JOVCHELEVICH; MOREIRA; LONDRES, 2014).

Como grande parte da produção de sementes de alface no país é realizada a pleno sol, o local de produção é dependente de clima, exigindo uma estação seca bem definida, que deve coincidir com a colheita. Essa característica pode ser um problema para agricultura familiar, pois distancia a produção de sementes dos campos de produção da hortaliça. Uma alternativa para locais onde o clima é considerado desfavorável pode ser o cultivo protegido em casas de vegetação, onde o agricultor possui maior controle dessas condições, proporcionando sementes de melhor qualidade.

A determinação da qualidade fisiológica das sementes, principalmente para o armazenamento, ganha destaque no manejo orgânico, pois permite fornecer sementes de qualidade por maior período. Nesse contexto, os testes de vigor são de extrema importância, visto que poucos trabalhos abordam o tema para sementes de alface e pouco se conhece a respeito das interações entre os ambientes de cultivo e o manejo no vigor das sementes. Entre os testes de vigor, o envelhecimento acelerado mostra-se uns dos mais sensíveis e eficientes para determinação do vigor das sementes (MARCOS FILHO, 2005).

Para sementes pequenas, como as de alface, o teste de envelhecimento acelerado pode causar danos excessivos a essas devido à grande variação no teor de água após o teste, provocando redução drástica na germinação (PANOBIANCO; MARCOS FILHO, 2001). Assim, para melhor resultado no teste devem-se utilizar técnicas que limitem a absorção de água pelas sementes, como na utilização de solução saturada de $\mathrm{NaCl}$, e que permitem a obtenção de umidades relativas inferiores às verificadas no envelhecimento acelerado convencional, sendo mais adequado para esse tipo de semente (JIANHUA; McDONALD, 1997).

Desta forma, objetivou-se avaliar a influência do ambiente de cultivo e de cultivares no vigor das sementes de alface produzidas em manejo orgânico e em dois municípios do estado do Rio de Janeiro.

\section{Material e métodos}

O experimento foi conduzido no Laboratório de Sementes do Instituto de Agronomia (IA) da Universidade Federal Rural do Rio de Janeiro (UFRRJ), município de Seropédica (RJ). Foi avaliado o vigor de lotes de sementes de cultivares de alface produzidas em manejo orgânico, em cultivo protegido e a céu aberto, nos municípios de Seropédica (RJ) e Avelar (RJ), no ano de 2013, com colheita realizada em outubro do mesmo ano. As cultivares utilizadas foram: Elisa, Regina 3500 e Vera do grupo lisa; Grands Rapids, Deyse e Maravilha quatro estações do grupo crespa e Grandes Lagos do tipo americana.

As sementes foram submetidas a determinações do grau de umidade, estabelecido pelo método da estufa a $105 \pm 3^{\circ} \mathrm{C}$, durante 24 horas, com duas amostras, com $1 \mathrm{~g}$ de sementes para cada tratamento, antes e após os períodos de envelhecimento acelerado com solução saturada de $\mathrm{NaCl}$ (EASS) (BRASIL, 2009). O EASS foi realizado em caixas de plástico transparente $(11 \times 11 \times 3,5 \mathrm{~cm})$, contendo em seu interior uma tela metálica acoplada e uma tela de nylon sobreposta para dar suporte às sementes e $40 \mathrm{~mL}$ de água destilada por igual quantidade de solução saturada de $\mathrm{NaCl}$ (40g em 100 mL de água) (JIANHUA; McDONALD, 1997). Após tampadas, as sementes foram mantidas no 
interior de câmaras de envelhecimento a $41{ }^{\circ} \mathrm{C}$ durante 72 horas. Decorrido o período de envelhecimento, as sementes foram colocadas para germinar.

Germinação: quatro repetições de 50 sementes foram semeadas em caixas de plástico transparente $(11 \times 11 \times 3,5 \mathrm{~cm})$ sobre papel de filtro umedecido com água destilada na proporção de 2,5 vezes o seu peso seco. As caixas foram mantidas em câmara de germinação a $25^{\circ} \mathrm{C}$ constantes, com fotoperíodo de oito horas. Realizou-se a primeira contagem aos quatro dias e a segunda aos sete, avaliando a porcentagem de plântulas normais (BRASIL, 2009).

O delineamento utilizado foi inteiramente casualizado, em esquema fatorial $(2 \times 7)$, com 4 repetições, sendo dois ambientes (cultivo protegido e céu aberto) e sete cultivares. Os dados foram submetidos à análise de variância e as médias comparadas pelo teste de Scott Knot $(P \leq 0,05)$, separadamente para cada município, por meio do Sistema de Análise Estatística SISVAR, versão 4.6 para microcomputadores (FERREIRA, 2003).

\section{Resultados e discussão}

Para as sementes produzidas no município de Seropédica, em cultivo protegido, o grau de umidade pré-EASS foi inferior para as cultivares Grandes Lagos, Deyse e Maravilha Quatro Estações. A céu aberto, a cultivar Grandes Lagos foi inferior às demais. Após o procedimento de EASS, o grau de umidade das sementes não apresentou diferença significativa entre as cultivares. Para as sementes produzidas no distrito de Avelar, não houve diferença estatística entre as cultivares pré-EASS tanto para cultivo protegido quanto para céu aberto. Pós-EASS no cultivo protegido, as cultivares Regina 3500 e Deyse foram estaticamente semelhantes e inferiores às demais. A céu aberto, constatou-se umidade inferior às demais na cultivar Elisa (TABELA 1).

Tabela 1. Umidade (\%) das sementes antes e após o teste de envelhecimento acelerado com solução saturada de $\mathrm{NaCl}$ (EASS).

\begin{tabular}{lrrrr}
\hline & \multicolumn{3}{c}{ SEROPÉDICA } \\
\hline \multirow{2}{*}{ CULTIVAR } & \multicolumn{2}{c}{ CULTIVO PROTEGIDO } & \multicolumn{2}{c}{ CÉU ABERTO } \\
\cline { 2 - 5 } & PRÉ-EASS & PÓS-EASS & PRÉ-EASS & PóS-EASS \\
\hline Elisa & $7,39 \mathrm{~A}$ & $7,73 \mathrm{~A}$ & $7,20 \mathrm{~A}$ & $7,66 \mathrm{~A}$ \\
Regina 3500 & $7,42 \mathrm{~A}$ & $7,98 \mathrm{~A}$ & $7,15 \mathrm{~A}$ & $7,58 \mathrm{~A}$ \\
Maravilha Quatro Estações & $6,82 \mathrm{~B}$ & $7,89 \mathrm{~A}$ & $7,04 \mathrm{~A}$ & $8,25 \mathrm{~A}$ \\
Grand Rapids & $7,16 \mathrm{~A}$ & $7,59 \mathrm{~A}$ & $7,07 \mathrm{~A}$ & $7,03 \mathrm{~A}$ \\
Deyse & $6,94 \mathrm{~B}$ & $8,41 \mathrm{~A}$ & $7,05 \mathrm{~A}$ & $8,02 \mathrm{~A}$ \\
Vera & $7,35 \mathrm{~A}$ & $7,38 \mathrm{~A}$ & $7,13 \mathrm{~A}$ & $8,11 \mathrm{~A}$ \\
Grandes Lagos & $6,96 \mathrm{~B}$ & $7,82 \mathrm{~A}$ & $6,61 \mathrm{~B}$ & $6,90 \mathrm{~A}$ \\
\hline CV 6,19 & \multicolumn{3}{c}{} \\
\hline
\end{tabular}




\begin{tabular}{lcrrr}
\hline \multicolumn{3}{c}{ AVELAR } & & \\
\hline & \multicolumn{3}{c}{ CULTIVO PROTEGIDO } & \multicolumn{2}{c}{ CÉU ABERTO } \\
\cline { 2 - 5 } & \multirow{2}{*}{ PRÉ-EASS } & PóS-EASS & PRÉ-EASS & PóS-EASS \\
\hline Elisa & $7,05 \mathrm{~A}$ & $8,64 \mathrm{~A}$ & $6,76 \mathrm{~A}$ & $7,65 \mathrm{~B}$ \\
Regina 3500 & $7,06 \mathrm{~A}$ & $7,99 \mathrm{~B}$ & $6,71 \mathrm{~A}$ & $9,21 \mathrm{~A}$ \\
Maravilha Quatro Estações & $7,23 \mathrm{~A}$ & $8,68 \mathrm{~A}$ & $6,70 \mathrm{~A}$ & $9,38 \mathrm{~A}$ \\
Grand Rapids & $7,31 \mathrm{~A}$ & $9,09 \mathrm{~A}$ & $6,99 \mathrm{~A}$ & $9,85 \mathrm{~A}$ \\
Deyse & $7,05 \mathrm{~A}$ & $8,19 \mathrm{~B}$ & $6,68 \mathrm{~A}$ & $9,01 \mathrm{~A}$ \\
Vera & $6,94 \mathrm{~A}$ & $8,73 \mathrm{~A}$ & $6,64 \mathrm{~A}$ & $9,23 \mathrm{~A}$ \\
Grandes Lagos & $7,40 \mathrm{~A}$ & $8,58 \mathrm{~A}$ & $6,90 \mathrm{~A}$ & $9,32 \mathrm{~A}$ \\
\hline CV 2,89 & & & & \\
\hline
\end{tabular}

Médias seguidas pela mesma letra na coluna não diferem entre si pelo teste Scott-Knott a 5\% de probabilidade.

Fonte: Elaboração do autor (2016).

As diferenças na absorção de água pelas sementes quando expostas à atmosfera úmida no teste de envelhecimento acelerado podem acarretar variações acentuadas no teor de água das sementes. As sementes utilizadas não passaram por classificação por tamanho, sendo que este pode interferir na absorção diferenciada de água. Para Powell (1995), alguns estudos conduzidos com espécies de sementes relativamente pequenas, como as de hortaliças, têm apresentado resultados menos consistentes devido à variação muito acentuada no grau de umidade ao final do período de envelhecimento. Sementes pequenas absorvem água de forma mais rápida e desuniforme em relação às sementes maiores durante o período de envelhecimento, o que pode acelerar o processo de deterioração ou apresentar variação de dados entre as sementes de uma mesma amostra e interferir na precisão dos resultados (JIANHUA; MCDONALD, 1997; BHÉRING et al., 2006).

Segundo Marcos Filho (1999), um dos principais indicadores da uniformidade das condições de envelhecimento acelerado é o grau de umidade das sementes ao final do teste, sendo que variações de 3 a $4 \%$ entre amostras são consideradas toleráveis. No trabalho desse autor, as cultivares que foram semelhantes ficaram dentro desse valor de referência e os que diferiram superaram esse valor.

Os resultados da Tabela 1 assemelham-se aos obtidos por Santos et al. (2011) em lotes de sementes de alface em duas cultivares. No referido trabalho, a umidade das sementes passou de 7,2 $\%$ para 8,4 \%, antes e pós-EASS, respectivamente. Por outro lado, no trabalho de Barbosa (2011), o aumento no grau de umidade foi maior, passando da média de 6 \% para $11 \%$ de umidade após o envelhecimento por 72 horas, com melhores resultados para indicação de vigor.

De acordo com Vieira (2012), em sementes de beterraba, as temperaturas mais elevadas, associadas aos maiores percentuais de umidade nas sementes, provocaram maior deterioração. Isso ocorre porque o grau de umidade influencia a ocorrência dos diferentes processos metabólicos que as sementes podem sofrer, ao passo que a temperatura afeta a velocidade dos processos bioquímicos (MARCOS FILHO, 2005).

Quanto à avaliação do potencial fisiológico das sementes de alface pelo teste de envelhecimento acelerado com solução salina de $\mathrm{NaCl}$, no município de Seropédica, em cultivo protegido, observa-se que os resultados para as cultivares Regina 3500 e Deyse foram estatisticamente iguais e inferiores às demais cultivares, considerando a primeira contagem de germinação (TABELA 2). Os 
menores valores de plântulas normais na primeira contagem foram para as cultivares Deyse, Vera e Grandes Lagos, de ciclo longo, quando a produção foi a céu aberto (TABELA 2).

Tabela 2. Porcentagens (\%) de plântulas normais na primeira e segunda contagem de cultivares de alface submetidas ao teste de envelhecimento acelerado em solução saturada de $\mathrm{NaCl}$.

\begin{tabular}{|c|c|c|c|c|}
\hline \multicolumn{5}{|c|}{ SEROPÉDICA } \\
\hline \multirow{2}{*}{ CULTIVAR } & $\begin{array}{c}\text { CULTIVO } \\
\text { PROTEGIDO }\end{array}$ & CÉU ABERTO & $\begin{array}{c}\text { CULTIVO } \\
\text { PROTEGIDO }\end{array}$ & CÉU ABERTO \\
\hline & \multicolumn{2}{|c|}{$1^{\text {a }}$ contagem $(\%)$} & \multicolumn{2}{|c|}{$2^{\mathrm{a}}$ contagem $(\%)$} \\
\hline Elisa & $86,50 \mathrm{Aa}$ & $63,50 \mathrm{Cb}$ & $93,00 \mathrm{Ba}$ & $70,50 \mathrm{Cb}$ \\
\hline Regina 3500 & $81,00 \mathrm{Ba}$ & $78,00 \mathrm{Ba}$ & $81,00 \mathrm{Ca}$ & $82,50 \mathrm{Ba}$ \\
\hline Maravilha Quatro Estações & $94,00 \mathrm{Aa}$ & $90,00 \mathrm{Aa}$ & $98,50 \mathrm{Aa}$ & $94,50 \mathrm{Aa}$ \\
\hline Grand Rapids & $93,00 \mathrm{Aa}$ & $90,50 \mathrm{Aa}$ & $96,50 \mathrm{Aa}$ & $92,50 \mathrm{Aa}$ \\
\hline Deyse & $70,50 \mathrm{Ba}$ & $37,00 \mathrm{Db}$ & $79,50 \mathrm{Ca}$ & $47,00 \mathrm{Db}$ \\
\hline Vera & $86,00 \mathrm{Aa}$ & $36,50 \mathrm{Db}$ & $91,00 \mathrm{Ba}$ & $48,00 \mathrm{Db}$ \\
\hline Grandes Lagos & $86,50 \mathrm{Aa}$ & $25,00 \mathrm{Db}$ & $88,00 \mathrm{Ba}$ & $33,50 \mathrm{~Eb}$ \\
\hline \multicolumn{5}{|l|}{ CV (\%) 5,23} \\
\hline \multicolumn{5}{|c|}{ AVELAR } \\
\hline \multirow{2}{*}{ CULTIVAR } & $\begin{array}{c}\text { CULTIVO } \\
\text { PROTEGIDO }\end{array}$ & CÉU ABERTO & $\begin{array}{c}\text { CULTIVO } \\
\text { PROTEGIDO }\end{array}$ & CÉU ABERTO \\
\hline & \multicolumn{2}{|c|}{$1^{a}$ contagem $(\%)$} & \multicolumn{2}{|c|}{$2^{\mathrm{a}}$ contagem $(\%)$} \\
\hline Elisa & $91,00 \mathrm{Ba}$ & $58,00 \mathrm{Ab}$ & $97,00 \mathrm{Aa}$ & $87,00 \mathrm{Ab}$ \\
\hline Regina 3500 & $95,00 \mathrm{Aa}$ & $57,50 \mathrm{Ab}$ & $98,00 \mathrm{Aa}$ & $89,00 \mathrm{Ab}$ \\
\hline Maravilha Quatro Estações & $99,00 \mathrm{Aa}$ & $48,00 \mathrm{Bb}$ & $99,00 \mathrm{Aa}$ & $69,50 \mathrm{Bb}$ \\
\hline Grand Rapids & $97,00 \mathrm{Aa}$ & $28,00 \mathrm{Cb}$ & $99,50 \mathrm{Aa}$ & $76,00 \mathrm{Bb}$ \\
\hline Deyse & $98,50 \mathrm{Aa}$ & $64,00 \mathrm{Ab}$ & $100,00 \mathrm{Aa}$ & $90,00 \mathrm{Ab}$ \\
\hline Vera & $97,50 \mathrm{Aa}$ & $59,00 \mathrm{Ab}$ & $97,50 \mathrm{Aa}$ & $88,00 \mathrm{Ab}$ \\
\hline Grandes Lagos & $89,50 \mathrm{Ba}$ & $24,00 \mathrm{Cb}$ & $93,00 \mathrm{Aa}$ & $91,00 \mathrm{Aa}$ \\
\hline CV (\%) $\quad 6,68$ & & & & \\
\hline
\end{tabular}

Médias seguidas pela mesma letra maiúscula na coluna e minúscula na linha não diferem pelo teste Scott-Knott a $5 \%$ de probabilidade.

Fonte: Elaboração do autor (2016).

Pelos resultados de segunda contagem observa-se que houve o agrupamento das cultivares em três grupos com relação ao vigor das sementes para cultivo protegido, um a mais do que na avaliação de primeira contagem. As cultivares Grand Rapids e Maravilha Quatro Estações foram semelhantes e superiores estatisticamente às demais. Menores valores foram das cultivares Regina 3500 e Deyse. Para cultivo a céu aberto, os resultados possibilitaram estratificar as cultivares em cinco grupos. Novamente, as cultivares Grand Rapids e Maravilha Quatro Estações foram superiores estatisticamente, seguidas da cultivar Regina 3500 e a cultivar Grandes Lagos, que apresentou o menor valor na avaliação de segunda contagem do EASS. Essas cultivares foram consideradas pouco resistentes ao pendoamento e de ciclo mais curto, fazendo com que a colheita ocorresse antes do início do período das chuvas, proporcionando sementes com a mesma qualidade fisiológica que as sementes produ- 
zidas em cultivo protegido. A elevação por longo período do grau umidade das sementes provocada por precipitação, próximo ao estado de maturação fisiológica, causa severos danos à qualidade das sementes.

No Distrito de Avelar, as cultivares Elisa e Grandes Lagos foram semelhantes entre si e inferiores às demais no cultivo protegido para o parâmetro primeira contagem de germinação. No cultivo a céu aberto, o teste possibilitou separar os lotes de sementes em três grupos quanto ao vigor pela primeira contagem. As cultivares Elisa, Regina 3500, Deyse e Vera foram semelhantes e superiores às demais. O vigor das sementes foi maior na produção em cultivo protegido para todas as cultivares avaliadas, considerando os resultados de primeira contagem (TABELA 2).

$\mathrm{Na}$ avalição de segunda contagem, na produção a céu aberto, as sementes das cultivares Grand Rapids e Maravilha quatro estações foram estatisticamente inferiores às demais, para segunda contagem. Em Avelar, o cultivo protegido foi estatisticamente superior à produção a céu aberto, para todas as cultivares, com exceção da cultivar Grandes, com resultados semelhantes para os dois ambientes de cultivo (TABELA 2).

Para determinação do potencial fisiológico das sementes de alface, a avaliação da germinação das sementes na segunda contagem aos sete dias possibilitou estratificar melhor as cultivares, principalmente as que foram produzidas a céu aberto (TABELA 2). De maneira geral, houve maior variação de vigor entre as cultivares no cultivo a céu aberto. Nessas condições, a avaliação na segunda contagem é mais indicada para determinação do vigor de sementes de alface.

A ocorrência de precipitação na época de colheita tanto na região de Seropédica quanto na de Avelar foi desfavorável para produção de sementes de alface a céu aberto para cultivares de ciclo longo, quando o transplante das mudas ocorre no outono-inverno. Todavia, em cultivo protegido, produziram-se sementes de alface com alta qualidade fisiológica independente das cultivares, sendo uma alternativa para a produção de sementes de elevada qualidade fisiológica.

\section{Conclusões}

A segunda contagem do teste de germinação, após o envelhecimento acelerado com solução saturada de $\mathrm{NaCl}$, possibilitou separar melhor os lotes de sementes de alface.

A produção em cultivo protegido proporcionou sementes de maior vigor, tanto em Seropédica, quanto em Avelar, pelo teste de envelhecimento acelerado com solução saturada de $\mathrm{NaCl}$.

As cultivares que produziram sementes de alto vigor, pelo teste de envelhecimento acelerado com solução saturada de $\mathrm{NaCl}$, foram a Grand Rapids e Maravilha Quatro Estações em ambos ambientes de cultivo.

\section{Agradecimentos}

À Faperj, pelo auxílio financeiro ao projeto: Processo: E-26/110.445/2014 (PRODUÇÃO E QUALIDADE DE SEMENTES DE ALFACE SOB CULTIVO ORGÂNICO EM DUAS LOCALIDADES DO ESTADO DO RIO DE JANEIRO EM DUAS ÉPOCAS DO ANO). 


\section{Accelerated aging of lettuce seeds produced under organic cultivation in greenhouse and in the open sky}

Lettuce seeds can be produced in natural conditions under full sun and in controlled conditions in greenhouses, where the cultivation environment can interfere with seed vigor. In this context, the accelerated aging with $\mathrm{NaCl}$ solution has proven efficient for determining the quality of the seeds. Therefore, the objective of this study is to evaluate the influence of cultivation environment and cultivars vigor of lettuce seeds produced in organic management, in two cities in the state of Rio de Janeiro. The design was completely randomized in a factorial scheme $(2 \times 7)$, with four replications, with two environments (protected and open cultivation) and seven lettuce cultivars. The experiment was conducted in Seropédica and Avelar cities (RJ), and the statistical analyzes were performed distinctly on each of them. The seeds were subjected to accelerated aging test with saturated $\mathrm{NaCl}$ solution and they were kept in a humid chamber with saline for $72 \mathrm{~h}$ at $41{ }^{\circ} \mathrm{C}$. After the aging period, the seeds were germinated. There were differences between the moisture content of the pre EASS seeds in Seropédica and post EASS in Avelar. Seeds produced in the greenhouse presented better results than those produced in the field for both Seropédica and Avelar cities. However, Grand Rapidis and Wonder Four Seasons cultivars showed high vigor for both the seeds produced in the greenhouse and in the field.

Keywords: Vigour. Vegetables. Lactuca sativa L.

\section{Referências}

ASSOCIAÇÃO BRASILEIRA DE COMÉRCIO DE SEMENTES E MUDAS. $2^{\circ}$ Levantamento de dados socioeconômicos da cadeia produtiva de hortaliças no Brasil: ano base 2012. Holambra, 2014. Disponível em: <http://www.abcsem.com.br/imagens_noticias/Apresenta\%C3\%A7\%C3\%A30\%20 completa\%20dos\%20dados\%20da\%20cadeia\%20produtiva\%20de\%20hortali\%C3\%A7as\%20 -\%2029MAI02014.pdf. >. Acesso em: 28 fev. 2017.

BARBOSA, R. M. Envelhecimento Acelerado em Sementes de Alface - Accelerated Aging in Lettuce Seeds." Ciência Rural, Santa Catarina, v. 41, n. 1, p. 1899-1902, 2011. Disponível em: http://www.scielo.br/scielo.php?script=sci_abstract\&pid=S0103=84782011001100008-\&lng=en\&nrm=i\&tIngpt>Acesso em: 20 fev. 2014.

BHÉRING, M. C.; DIAS, D. C. F. S.; VIDIGAL, D. S.; NAVEIRA, D. S. P. Teste de envelhecimento acelerado em sementes de pimenta. Revista Brasileira de Sementes, Brasília, v. 28, n. 3, p. 64-71, 2006. Disponível em: <http://www.scielo.br/scielo.php?pid=S0101 -31222006000300010\&script=sci_ abstract \&tIng=pt> Acesso em: 26 fev. 2014.

BRASIL. Ministério da Agricultura e Reforma Agrária. Secretaria Nacional de Defesa Agropecuária. Departamento Nacional de Produção Vegetal. Coordenação de Laboratório Vegetal. Regras para Análise de Sementes. Brasília, DF: Mapa/Acessoria de comunicação social, 2009. 399p. Disponível em: <http://www.agricultura.gov.br/assuntos/insumos-agropecuarios/arquivos-publicacoes-insumos/2946_regras_analise_sementes.pdf> Acesso em: 26 jan. 2013. 
FERREIRA, D. F. Software Sisvar: Versão 4.6 (Build 6.0). Lavras: DEX/UFLA, 2003. Disponível em: <http://www.dex.ufla.br/danielff/prog.htm>. Acesso em: 6 fev. 2014.

JIANHUA, Z.; McDONALD, M. B. The saturated salt accelerated aging test for small seeded crops. Seed Science and Technology, v. 25, p. 123-131, 1997.

JOVCHELEVICH, P.; MOREIRA, V. R. R.; LONDRES, F. Rede de sementes biodinâmicas reconstruindo a autonomia perdida na produção de hortaliças. Revista Agriculturas, Rio de Janeiro, v. 1, n. 1, p. 38-44, 2014. Disponível em: <http://aspta.org.br/wp-content/uploads/2014/05/Caderno-ANA-Sementes-2014-ABD.pdf>. Acesso em: 6 fev. 2017.

MARCOS-FILHO, J. Teste de envelhecimento acelerado. In: KRZYZANOWSKI, F. C.; VIEIRA, R. D.; FRANÇA NETO, J. B. (Ed.). Vigor de sementes: conceitos e testes. Londrina: ABRATES, 1999. cap. 3, p. 1-24.

MARCOS-FILHO J. Deterioração de sementes. In. vadas. Edição: 1 Piracicaba: FEALQ, 2005. Cap.8, p. 291-352.

PANOBIANCO, M.; MARCOS FILHO, J. Envelhecimento acelerado e deterioração controlada em sementes de tomate. Scientia Agricola, Piracicaba, v. 58, n. 3, p. 525-531, 2001. Disponível em: $<$ http://www.scielo.br/scielo.php?script=sci_arttext\&pid=S0103=90162001000300014-\&lngen> Acesso em: 26 jan. 2017.

POWELL, A. A. The controlled deterioration test. In: VERTER HA. Seed vigor testing seminar. Zürich: ISTA, 1995. p. 73-87.

SANTOS, F.; TRANI, P. E.; MEDINA, P. F.; PARISI, J. J. D. Teste de envelhecimento acelerado para avaliação da qualidade de sementes de alface e almeirão. Revista Brasileira de Sementes, v. 33, n. 2, p. 322-30, 2011. Disponível em: <http://www.scielo.br/scielo.php?pi$\mathrm{d}=$ S0101-31222011000200015\&script=sci_abstract\&tIng=pt $>$. Acesso em: 26 jan. 2017.

VIEIRA, R. D. Deterioração controlada para avaliar o potencial fisiológico de sementes de beterraba. Horticultura Brasileira, v. 30, p. 379-84, 2012. Disponível em: <http://www.scielo.br/scielo. php?pid=S0102-5362012000300004\&script=sci_abstract\&tlng=pt $>$. Acesso em: 26 jan. 2017. Histórico editorial:

Submetido em: 04/11/2016.

Aceito em: 16/10/2017. 
Como citar:

ABNT

BRANDÃO, A. A.; LOPES, H. M. Envelhecimento acelerado de sementes de alface produzidas no manejo orgânico em cultivo protegido e a céu aberto. Revista Agrogeoambiental, Pouso Alegre, v. 10, n. 4, p. 55-64, dez. Doi: http://dx.doi.org/10.18406/2316-1817v10n420181136

APA

BRANDÃO, A. A. \& LOPES, H. M. (2018). Envelhecimento acelerado de sementes de alface produzidas no manejo orgânico em cultivo protegido e a céu aberto. Revista Agrogeoambiental, 10 (4), 55-64. Doi: http:// dx.doi.org/10.18406/2316-1817v10n420181136

ISO

BRANDÃO, A. A. E LOPES, H. M. Envelhecimento acelerado de sementes de alface produzidas no manejo orgânico em cultivo protegido e a céu aberto. Revista Agrogeoambiental, 2018, vol. 10, n. 4, pp. 55-64. Eissn 2316-1817. Doi: http://dx.doi.org/10.18406/2316-1817v10n420181136

\section{VANCOUVER}

BRANDÃO AA, LOPES HM. Envelhecimento acelerado de sementes de alface produzidas no manejo orgânico em cultivo protegido e a céu aberto. Rev agrogeoambiental. 2018 dez.; 10(4): 55-64.

Doi: http://dx.doi.org/10.18406/2316-1817v10n420181136 